\title{
Severe Organizing Pneumonia after Two Cycles of Docetaxel as Fourth-Line Chemotherapy for Advanced Non-Small Cell Carcinoma of the Lung
}

\author{
Jens Hasskarl ${ }^{\mathrm{a}}$ Percy Schroettner ${ }^{\mathrm{a}}$ Andrea von den Berg ${ }^{\mathrm{a}}$ \\ Anja Rueckert ${ }^{\mathrm{a}}$ Alex Frydrychowicz ${ }^{\mathrm{b}} \quad$ Gian Kayser $^{\mathrm{c}}$ \\ Cornelius F. Waller \\ aDepartment of Hematology and Oncology, University of Freiburg Medical Center, \\ bDepartment of Diagnostic Radiology, Medical Physics, University Hospital \\ Freiburg, and 'Institute of Pathology, Freiburg Medical School, Freiburg, Germany
}

\section{Key Words}

Docetaxel $\cdot$ Taxane $\cdot$ Bronchiolitis obliterans organizing pneumonia, BOOP $\cdot$ Organizing pneumonia, OP

\begin{abstract}
Organizing pneumonia (formerly known as bronchiolitis obliterans organizing pneumonia, BOOP) is an inflammatory process of the bronchioles that can lead to the destruction of small airways and surrounding lung tissue. Although the majority of cases are idiopathic, certain chemicals and drugs can induce OP. Here, we report a 54-year-old male patient with advanced non-small cell lung cancer (NSCLC) who developed therapyassociated OP. He had undergone several other chemotherapies before being switched to docetaxel as monotherapy $\left(75 \mathrm{mg} / \mathrm{m}^{2}\right)$. Treatment was initially well tolerated, but after the second cycle the patient developed increasing shortness of breath. Computed tomography (CT) for staging after the second cycle showed bilateral predominantly interstitial infiltration highly suggestive of acute lung fibrosis. Bronchoscopy revealed signs of chronic bronchitis and watery discharge from both lungs. Bronchoalveolar lavage and transbronchial needle biopsy was performed. Based on histopathologic examination, diagnosis of OP was made. After cessation of docetaxel and initial high dose steroids, the infiltration ameliorated rapidly. This is the second case in the literature that associates docetaxel with rapid onset of bronchiolitis obliterans. Therefore, patients with lung cancer receiving docetaxel who develop respiratory symptoms should be suspected to develop OP.
\end{abstract}




\begin{tabular}{|c|c|c|c|}
\hline $\begin{array}{l}\text { Cose Reports in } \\
\text { Binatily }\end{array}$ & $\begin{array}{l}\text { Case Rep Oncol 2009;2:12-19 } \\
\text { D0I: } 10.1159 / 000200015\end{array}$ & Published online: February 16, 2009 & $\begin{array}{l}\text { @ } 2009 \text { S. Karger AG, Basel } \\
\text { ISSN 1662-6575 } \\
\text { www.karger.com/cro }\end{array}$ \\
\hline
\end{tabular}

\section{Case Report}

The patient, a 54-year-old Caucasian male, had been diagnosed with NSCLC in 2006. At the time of primary diagnosis, he had been suffering from increasing shortness of breath due to malignant pericardial effusion that contained carcinoembryonic antigen (CEA)-positive cancer cells. Apart from smoking (50 pack-years), his past medical history had been unremarkable. After diagnosis of inoperable NSCLC Stage IIIB (bilateral malignant pleural and pericardial effusion, bilateral lymph node involvement, UICC $\mathrm{cT}_{4} \mathrm{~N}_{3} \mathrm{M} 0$; IASLC proposed staging system $\mathrm{cT}_{4} \mathrm{~N}_{3} \mathrm{M} 1 \mathrm{a}$ ), the patient was started on first-line chemotherapy with gemcitabine $\left(1,000 \mathrm{mg} / \mathrm{m}^{2}\right)$ and cisplatin $\left(70 \mathrm{mg} / \mathrm{m}^{2}\right)$. After the first cycle of chemotherapy, pericardial effusion was no longer detectable. Because of hearing changes, therapy was continued with gemcitabine $\left(1,000 \mathrm{mg} / \mathrm{m}^{2}\right)$ and carboplatin (AUC5) for 5 additional cycles. Staging CTs showed stable bilateral mediastinal lymphadenopathy and small pericardial effusion. In the course of treatment, the patient developed Raynaud's syndrome which was treated with calcium channel antagonists. Because of increasing CEA, therapy with erlotinib $(150 \mathrm{mg} / \mathrm{d})$ was initiated in December 2006. Unfortunately, this led to an exacerbation of Raynaud's syndrome. In February 2007, systemic therapy with pemetrexed $\left(500 \mathrm{mg} / \mathrm{m}^{2} \mathrm{~d} 1 \mathrm{q} 3\right.$ weeks) was initiated and given for a total of 3 cycles, when the patient refused further treatment because of polyneuropathic symptoms. CT scan and FDG-PET in July 2007 revealed increasing PET-positive mediastinal and supraclavicular lymph nodes corresponding to a further increase of serum CEA levels. Pericardial effusion was stable. In August 2007, the patient consulted the emergency room with tachycardia and increased shortness of breath. Ultrasound revealed large pericardial effusion which was drained. Cytology again revealed CEA-positive tumour cells. A corresponding increase of CEA was noted (fig. 1). After stabilization, systemic chemotherapy with docetaxel $\left(75 \mathrm{mg} / \mathrm{m}^{2} \mathrm{~d} 1 \mathrm{q} 21 \mathrm{~d}\right)$ was started and continued for 2 cycles. During this time, regular heart ultrasound showed stable, non-haemodynamically relevant pericardial effusion. Serum CEA levels showed a rapid decline, suggesting good antitumour effect of docetaxel (fig. 1). Nevertheless, the patient suffered from increasing dyspnoea and orthopnoea that required hospitalization. Staging CT showed predominantly hyperdense interstitial thickening with sporadic alveolar infiltrates most prominent in the dorsobasal parts of the lung (fig. 2). The findings were symmetrically distributed on both sides (fig. 2B) and had not been detectable in the initial chest CT 2 months before (fig. 2A). Since ground glass opacifications or patchy attenuation patterns were not seen, the findings were summarized as a subpleural fibrosis. Since organizing pneumonia was not a differential diagnosis at the time of the examination and no ground glass infiltrates were seen, a combination of in- and expiratory multislice CT scans was not performed. Apart from progressive pericardial effusion, there was no pleural effusion, or enlarged lymph nodes.

Bronchoscopy showed signs of chronic bronchitis, but no acute infection or tumour invasion. Bronchoalveolar lavage was performed and transbronchial biopsies were taken. No viruses or microbiological pathogens could be isolated. Pathological analysis showed unspecific chronic inflammation reaction with granulation tissue in the small bronchi and alveoli similar to OP (fig. 3 ).

Therapy with prednisone $(1 \mathrm{mg} / \mathrm{kg})$ was initiated and resulted in a rapid improvement of respiratory symptoms. After tapering steroids, the patient was discharged on $10 \mathrm{mg}$ prednisone daily. Control CT scans were performed 2 and 4 months after the diagnosis. Of note was the overt reduction of subpleural interstitial thickening and the sporadic alveolar infiltrates (see fig. 2C). Still, no patchy alveolar infiltrates or ground glass opacifications were detectable. After 1 cycle of vinorelbine $\left(25 \mathrm{mg} / \mathrm{m}^{2}\right.$ weekly q 6 weeks), staging CT showed stable disease and markedly improved pulmonary changes (fig. 2C). The patient was free of respiratory symptoms. On the patient's request, therapy was halted. During further follow-up by repeated CTs, progressive disease and increasing pericardial effusion were diagnosed (fig. 2D), so that in February 2008 the pericardium was fenestrated to allow drainage into the left pleural space. In April 2008, a pleurodesis for recurrent pleural effusion was performed.

\section{Discussion}

$\mathrm{OP}$ is a relatively rare syndrome with characteristic clinical, radiological and pathological findings. It is characterized by inflammation and destruction (obliteration) of the bronchioles and surrounding tissue in the lungs [1]. Typically, infiltrates are not resolved, but form fibrous tissue in the alveoli. The clinical features and radiological imaging may resemble infectious pneumonia [2]. However, diagnosis is suspected when there is no response to multiple antibiotics, and blood and sputum cultures are negative for organisms. Approximately $50 \%$ of OP cases are idiopathic, but multiple OP-inducing 
factors, such as drugs [1], infection, radiation therapy, aerosols and chronic inflammatory diseases, have been described [3]. OP often develops on grounds of pre-existing chronic inflammatory diseases or as adverse effect to certain drugs (for an excellent review, see $[4])$.

Symptoms are variable and unspecific. Patients may present with flu-like complaints, low-grade fever, non-productive cough and (increasing) shortness of breath. Often, these symptoms are interpreted as infection and treated with broad-spectrum antibiotics without clinical improvement. On clinical examination, uni- or bilateral pulmonary crackles may be heard [5].

Laboratory tests are unspecific and may show signs of infection. Pulmonary function is often compromised. Plain chest radiography may show characteristic patchy unilateral or bilateral consolidation areas and/or small nodular opacities, but may show unspecific findings as well. Specific signs such as ground glass appearances are uncommon on standard chest radiographs. CT scans are most sensitive to assess involvement and distribution of pulmonary changes. Typically, OP is characterized by multiple, predominantly bilateral patchy air space opacities disseminated throughout both lungs. Other patterns include interstitial (reticular, nodular or reticulonodular) opacities, focal consolidations or nodules or masses [6]. Pleural effusions may be present, but are not typical $[3,7]$. Nevertheless, the diagnosis of OP cannot reliably be made solely on radiologic grounds, as findings are unspecific. Acute fibrosis as possibly detectable in idiopathic interstitial fibrosis includes a variety of possible findings. The lower and subpleural parts of the lung are affected predominantly or exclusively. With respect to the severity of the disease, the findings change and the initial irregular linear pattern becomes more diffuse. Traction bronchiectasis may appear, and even honey-combing can be appreciated. Bronchoscopy shows unspecific changes. Cytological findings in bronchoalveolar lavage samples are characteristic, but unspecific (increases in the percentages of neutrophils and lymphocytes, decreased CD4+/CD8+ ratio, and activation of T cells). A reliable diagnosis should be based on histopathologic analysis of transbronchial or open biopsies.

OP may resolve spontaneously, but patients usually require treatment with steroids. The overall mortality rate in patients with OP is approximately $10 \%$. Most patients with OP respond to treatment with steroids, and symptoms resolve within days or weeks. Radiographic findings reportedly demonstrate improvement in $50-86 \%$ of patients; however, in a minority of patients, the disease may persist. Approximately $30 \%$ of patients experience relapses upon withdrawal of treatment. A standardized approach to dosing starting at $0.75 \mathrm{mg} / \mathrm{kg}$ and weaning over 24 weeks has been shown to reduce total corticosteroid exposure without affecting outcome.

\section{Conclusion}

We here report a case of OP (formerly known as BOOP) that developed after treatment with docetaxel for advanced NSCLC in a fourth-line chemotherapy setting. To our knowledge, this is the second report of OP or pulmonary fibrosis that can be directly attributed to docetaxel therapy. One prior case reported OP secondary to combination chemotherapy with docetaxel and gemcitabine for bronchoalveolar carcinoma [8], although others have reported pulmonary fibrosis and interstitial pneumonitis $[9,10]$. Furthermore, docetaxel is known to induce fibrosis of the skin and its appendages [1113]. Although other chemotherapeutic agents have been reported to induce OP, docetaxel 


\begin{tabular}{|c|c|c|c|}
\hline $\begin{array}{c}\text { Cose Reports in } \\
\text { Oncion't }\end{array}$ & $\begin{array}{l}\text { Case Rep Oncol 2009;2:12-19 } \\
\text { D0I: 10.1159/000200015 }\end{array}$ & Published online: February 16, 2009 & $\begin{array}{l}\text { @ } 2009 \text { S. Karger AG, Basel } \\
\text { ISSN 1662-6575 } \\
\text { www.karger.com/cro }\end{array}$ \\
\hline
\end{tabular}

has been regarded to have mainly non-pulmonary toxicities, mainly cytopenia and polyneuropathy. Although it is a potent drug for treatment of various solid tumour entities, docetaxel might cause serious pulmonary side effects. In a poster presented by Ahn et al. at the 2008 joint IASLC and ESMO conference [14], the authors report a high incidence of docetaxel-related pneumonitis of $17 \%$ in patients receiving treatment for lung cancer. Given our findings that CT-morphological changes interpreted as pulmonary fibrosis turned out to be bronchiolitis obliterans pneumonia, one has to worry about the true incidence of OP. So, if a patient receiving docetaxel develops respiratory distress and radiographic changes suggestive of alveolar consolidation, OP must be differentiated from infectious pneumonia, as treatment and prognosis are different.

Fig. 1. Carcinoembryonic antigen (CEA) serum levels over time. CEA levels ( $\mathrm{ng} / \mathrm{ml}$ ) were measured using standardized laboratory tests (Roche, Germany) from routine blood samples to measure disease activity and therapy effects. The indicated chemotherapies were given as depicted (arrows). Gem = Gemcitabine $1,000 \mathrm{mg} / \mathrm{m}^{2}(\mathrm{~d} 1,8)$; Cis = cisplatin $70 \mathrm{mg} / \mathrm{m}^{2}(\mathrm{~d} 1) \mathrm{q} 21 \mathrm{~d}$; Carbo = carboplatin AUC $5(\mathrm{~d} 1)$; erlotinib $150 \mathrm{mg} / \mathrm{d}$, pemetrexed $500 \mathrm{mg} \mathrm{mg} / \mathrm{m}^{2}$ q 21d; docetaxel $75 \mathrm{mg} / \mathrm{m}^{2} \mathrm{q} 21 \mathrm{~d}$; vinorelbin $25 \mathrm{mg} / \mathrm{m}^{2}$ weekly. Pericardial fenestration to the left pleural space was performed because of symptomatic therapyresistant pericardial effusion.

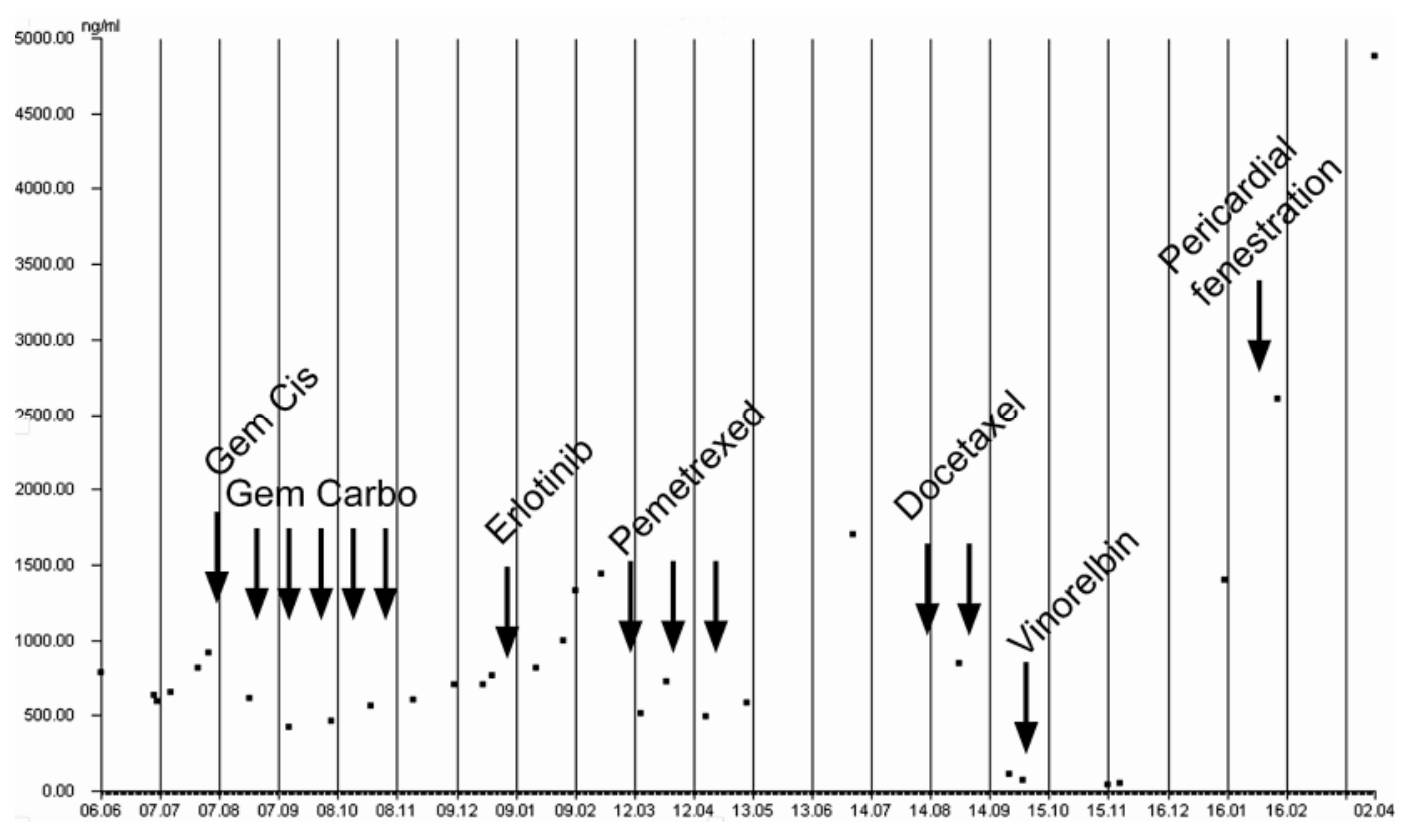




\begin{tabular}{|c|c|c|c|}
\hline $\begin{array}{r}\text { Cose Reports in } \\
\text { Eincisily }\end{array}$ & $\begin{array}{l}\text { Case Rep Oncol 2009;2:12-19 } \\
\text { Dol: } 10.1159 / 000200015\end{array}$ & Published online: February 16, 2009 & $\begin{array}{l}\text { @ } 2009 \text { S. Karger AG, Basel } \\
\text { ISSN 1662-6575 } \\
\text { www.karger.com/cro }\end{array}$ \\
\hline
\end{tabular}

Fig. 2. CT scans 2 months before (A), at onset of clinical symptoms (B), 2 months $(\mathbf{C})$ and 4 months (D) after presentation. After two cycles docetaxel, the patient complained about rapidly worsening shortness of breath. Routine chest CT showed subpleural interstitial thickening with a reticular pattern and sporadic alveolar infiltrates, highly suggestive of fibrosis (B). The typical distribution pattern was bilateral and most prominent in the ventrobasal parts of the lung. The initial thoracic CT and plain chest radiographs were free of signs indicating pneumonia, fibrosis or alveolitis $(\mathbf{A})$. There was no pleural effusion and no alveolar infiltrates, but significant pericardial effusion. Control CT scans performed 2 (C) and 4 (D) months after the onset of dyspnoea showed significant improvement. Contrast-enhanced multislice CT of the chest was performed with a 64-slice scanner (Somatom Sensation 64, Siemens, Germany) during breath-hold in inspiration. The field of view was adapted to the patient's anatomy and covered a craniocaudal range including the adrenal glands. Standard image settings were: collimation $1.2 \mathrm{~mm}$, reconstructed to slice thickness of 3.0 and $1.5 \mathrm{~mm}$ with a medium soft reconstruction kernel for mediastinal structures (B31f) and a moderately hard kernel for the interpretation of pulmonary structures (B60). Image interpretation was performed on a TIANI workstation (TIANI Medgraph, Austria) with the window level setting 50/350 for soft tissue interpretation and $-500 / 1,400$ for the evaluation of pulmonary structures, and could be manually adapted to the needs of the radiologist. 


\begin{tabular}{c|l|l|l}
$\begin{array}{c}\text { Cose Reports in } \\
\text { Oncolojy }\end{array}$ & $\begin{array}{l}\text { Case Rep Oncol 2009;2:12-19 } \\
\text { D01: 10.1159/000200015 }\end{array}$ & & $\begin{array}{l}\text { Published online: February 16, 2009 S. Karger AG, Basel } \\
\text { ISSN 1662-6575 } \\
\text { www.karger.com/cro }\end{array}$ \\
\hline
\end{tabular}

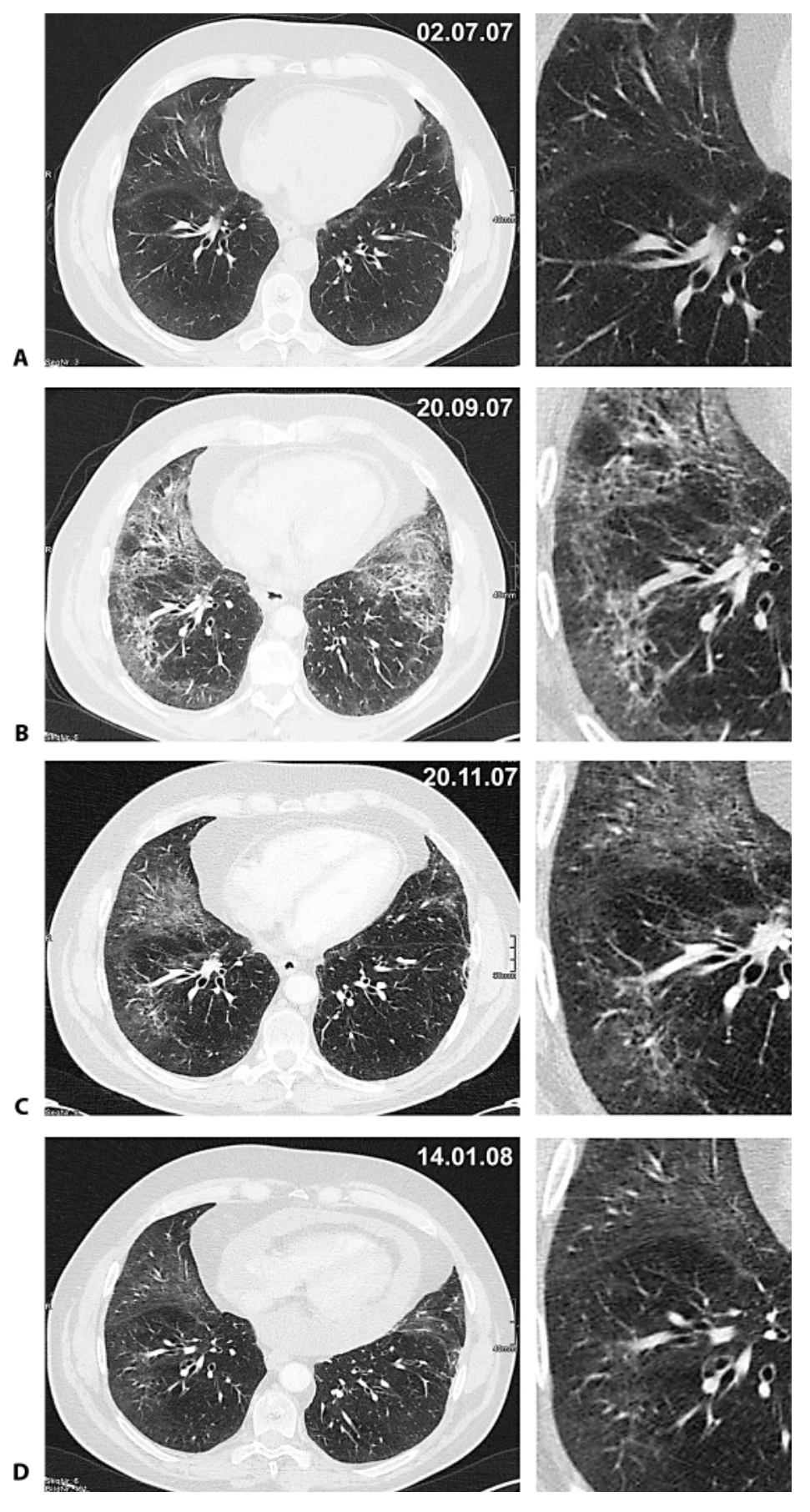




\begin{tabular}{c|l|l|l}
$\begin{array}{c}\text { Cose Reports in } \\
\text { Oncolayly }\end{array}$ & $\begin{array}{l}\text { Case Rep Oncol 2009;2:12-19 } \\
\text { D0I: 10.1159/000200015 }\end{array}$ & Published online: February 16, 2009 & $\begin{array}{l}\text { O 2009 S. Karger AG, Basel } \\
\text { ISSN 1662-6575 } \\
\text { www.karger.com/cro }\end{array}$ \\
\hline
\end{tabular}

Fig. 3. Histopathologic diagnosis of organizing pneumonia. Peribronchial lung parenchyma with newly formed intra-alveolar fibrous foci, as typical morphologic feature of organizing pneumonia. a HE. $\times 40$. b HE. $\times 100$. c Elastica van Gieson stain. $\times 100$.
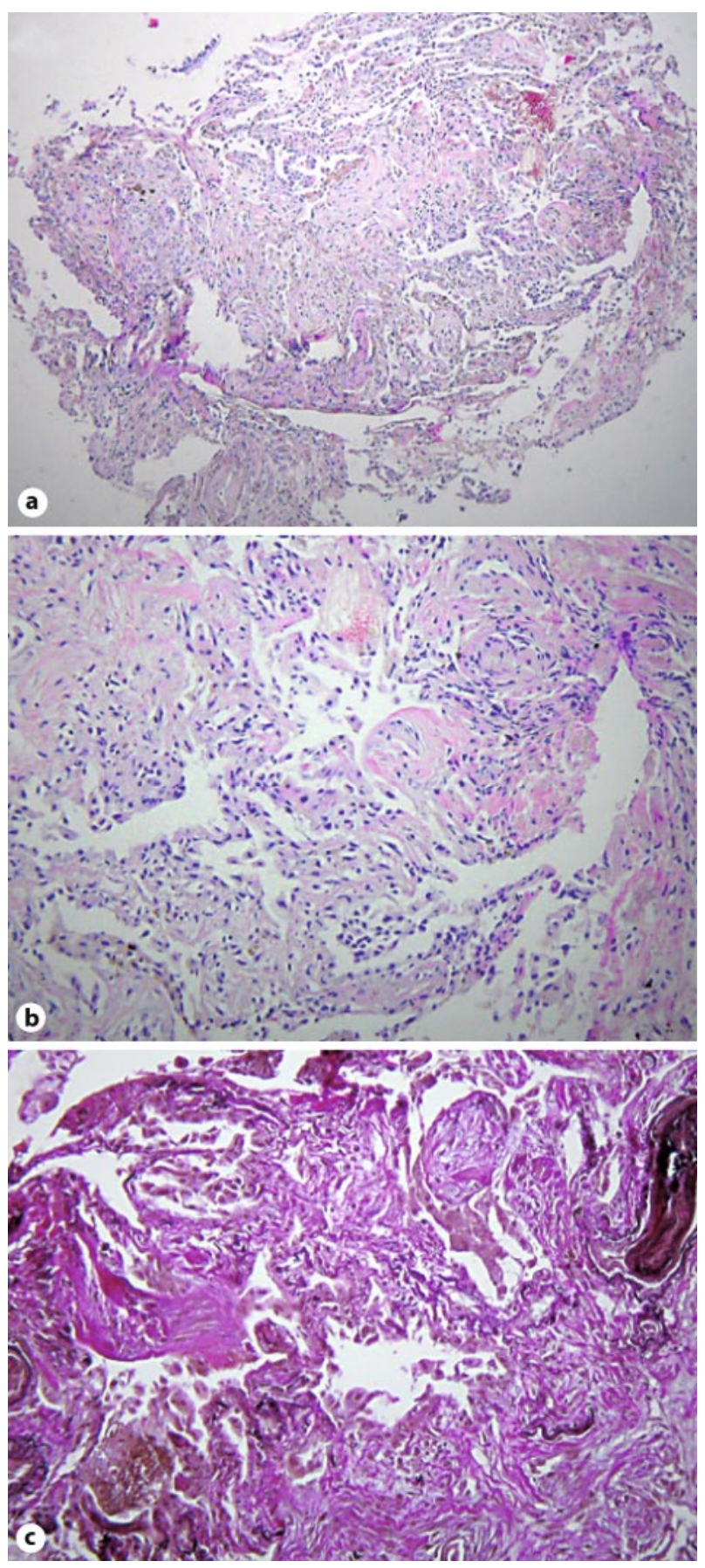


\begin{tabular}{|c|c|c|c|}
\hline $\begin{array}{c}\text { Cose Reports in } \\
\text { incion' }\end{array}$ & $\begin{array}{l}\text { Case Rep Oncol 2009;2:12-19 } \\
\text { Dol: 10.1159/000200015 }\end{array}$ & Published online: February 16, 2009 & \begin{tabular}{|l} 
@ 2009 S. Karger AG, Basel \\
ISSN 1662-6575 \\
www.karger.com/cro
\end{tabular} \\
\hline
\end{tabular}

\section{References}

1 Epler GR: Drug-induced bronchiolitis obliterans organizing pneumonia. Clin Chest Med 2004;25:89-94.

2 Lamont J, Verbeken E, Verschakelen J, Demedts M: Bronchiolitis obliterans organising pneumonia. A report of 11 cases and a review of the literature. Acta Clin Belg 1998;53:328-336.

-3 Oymak FS, Demirbas HM, Mavili E, et al: Bronchiolitis obliterans organizing pneumonia. Clinical and roentgenological features in 26 cases. Respiration 2005;72:254-262.

-4 Epler GR: Bronchiolitis obliterans organizing pneumonia. Arch Intern Med 2001;161:158-164.

5 Cordier JF, Loire R, Brune J: Idiopathic bronchiolitis obliterans organizing pneumonia. Definition of characteristic clinical profiles in a series of 16 patients. Chest 1989;96:999-1004.

6 Fraser RS, Müller NL, Colman CD, Paré PD: Fraser and Paré's Diagnosis of Diseases of the Chest, 4 ed. Philadelphia, WB Saunders, 1999.

7 Müller NL, Coiby TV: Idiopathic interstitial pneumonias: high-resolution CT and histologic findings. Radiographics 1997;17:1016-1022.

8 Cobo Dols M, Gil Calle S, Ales Diaz I, et al: Bronchiolitis obliterans organizing pneumonia simulating progression in bronchioloalveolar carcinoma. Clin Transl Oncol 2006;8:133-135.

9 Grande C, Villanueva MJ, Huidobro G, Casal J: Docetaxel-induced interstitial pneumonitis following non-small-cell lung cancer treatment. Clin Transl Oncol 2007;9:578-581.

10 Leimgruber K, Negro R, Baier S, et al: Fatal interstitial pneumonitis associated with docetaxel administration in a patient with hormone-refractory prostate cancer. Tumori 2006;92:542-544.

11 Esmaeli B, Burnstine MA, Ahmadi MA, Prieto VG: Docetaxel-induced histologic changes in the lacrimal sac and the nasal mucosa. Ophthal Plast Reconstr Surg 2003;19:305-308.

12 Kupfer I, Balguerie X, Courville P, Chinet P, Joly P: Scleroderma-like cutaneous lesions induced by paclitaxel: a case study. J Am Acad Dermatol 2003;48:279-281.

13 Esmaeli B, Valero V, Ahmadi MA, Booser D: Canalicular stenosis secondary to docetaxel (taxotere): a newly recognized side effect. Ophthalmology 2001;108:994-995.

14 Ahn MI, Kim HK, Kim CH, et al: 134P: computed tomographic findings of docetaxel-induced pneumonitis in non-small cell lung cancer patients; in Jett J (ed): 1st European Lung Cancer Conference, April 2008, Geneva, Switzerland. J Thorac Oncol 2008;3(suppl 1):S9-S98. 